\title{
Studies on Nitrosylruthenium Complexes in Nitric Acid Using Repeated Extractions
}

\author{
G. RUDSTA M *
}

The Gustaf Werner Institute for Nuclear Chemistry, University of Uppsala, Sweden

\begin{abstract}
Repeated extractions using the system tri-n-butyl phosphate (TBP) - nitric acid have been applied to the study of nitrosylruthenium nitrates. A detailed investigation of the partition coefficients has been carried out. The equilibrium composition of a solution of nitrosylruthenium nitrates in aqueous nitric acid has been determined, and the kinetics of the interchange between the complexes have been studied.
\end{abstract}

\begin{abstract}
Tn the presence of oxides of nitrogen, ruthenium easily forms strong nitroso 1 complexes. These complexes have recently attracted much attention because some of them are effectively extracted by tributyl phosphate. The extraction with tributyl phosphate from nitric acid solutions is a method often used for the separation of uranium and plutonium from fission products. There are two ruthenium isotopes with long half-lives and high fission yields among the fission products ${ }^{1}$, namely ${ }^{103} \mathrm{Ru}$ and ${ }^{106} \mathrm{Ru}$, and ruthenium therefore causes difficulties in the separation process.

Several investigations of the nitrato complexes of nitrosylruthenium have been published ${ }^{2-9}$. In the present investigation an extraction method has been worked out which makes accurate determinations of concentrations and partition coefficients possible. This technique has been used for a study of (a) the composition of a solution of nitrosylruthenium nitrates in aqueous nitric acid as a function of the acidity, (b) the kinetics of the interchange between the complexes, and (c) the dependence of the partition coefficients on various factors such as the tributyl phosphate concentration, the nitric acid concentration, and the temperature.
\end{abstract}

* Now at CERN, Geneva, Switzerland. 


\section{THE METHOD OF REPEATED EXTRACTIONS}

\section{Independent constituents}

A solution (water phase) containing $i$ independent constituents of the concentrations $c_{i}$ is extracted repeated times with the same volume of an immiscible liquid (organic phase). The coefficients for the partition of the constituents between the organic phase and the water phase are denoted by $q_{i}$. For the sake of simplicity, the symbols $p_{i}$ are introduced by the relation

$$
p_{i}=\frac{q_{i}}{1+q_{i}}
$$

The $n$ :th organic phase will contain the compounds in the total concentration $\left(C_{o}\right)_{n}$ :

$$
\left(C_{o}\right)_{n}=\sum_{i} c_{i} q_{i}\left(1-p_{i}\right)^{n}
$$

For large values of $n$ the constituent with the smallest partition coefficient $\left(=p_{1}\right)$ will dominate. If $\log \left(C_{o}\right)_{n}$ is plotted versus $n$ a straight line is then obtained:

$$
\log \left(C_{o}\right)_{n} \rightarrow \log c_{1} q_{1}+n \log \left(1-p_{1}\right)
$$

This line has the slope $\log \left(1-p_{1}\right)$, and its intercept with the $\log C_{o}$-axis is equal to $\log c_{1} q_{1}$. Thus $q_{1}$ and $c_{1}$ can be determined. By the subtraction of $c_{1} q_{1}\left(1-p_{1}\right)^{n}$ from eqn. (2) a new function $\left(C_{o, d}\right)_{n}$ is obtained. This function can be plotted versus $n$ on a semilogarithmic scale and be used for a determination of the partition coefficient and the concentration of the constituent with the next smallest partition coefficient. The same procedure can be repeated to yield the partition coefficients and the concentrations of the remaining constituents of the solution provided that the partition coefficients are sufficiently different *.

If $p_{1}$ is very small, eqn. (3) corresponds to a line with a small slope, and it is difficult to determine the partition coefficient. For large values of $n$, however, one obtains

$$
\frac{\left(C_{o}\right)_{n}}{\left(C_{w}\right)_{n}} \rightarrow q_{1}
$$

where $\left(C_{w}\right)_{n}$ is the total concentration in the water phase after the $n$ :th extraction. The smallest partition coefficient $q_{1}$ is determined by plotting the concentration ratio versus $n$.

By repeated extractions of an organic phase with water phases (equal volumes) similar results are obtained:

$$
\left(C_{w}^{\prime}\right)_{n}=\sum_{i} \frac{c_{i}}{q_{i}} p_{i}^{n}
$$

(Primed symbols refer in this work to repeated extractions of an organic phase).

* This method of analysis is analogous to the resolution of a complex decay curve of a number of radioactive isotopes into its components. 
On a semilogarithmic scale, $\left(C_{w}^{\prime}\right)_{n}$ can be resolved into a number of straight lines with their slopes equal to $\log p_{i}$ and their intercepts with the $\log C_{w}^{\prime}$-axis equal to $\log c_{i} / q_{i}$. The concentration ratio (eqn. (4)) gives in this case the largest partition coefficient.

Repeated extractions of a water phase containing dependent constituents (nitrosylruthenium nitrates)

If the constituents of a solution are dependent of each other, the method of analysis just outlined must be changed in order to take this into account. The nitrosylruthenium nitrates interchange rapidly, and they cannot be considered as independent.

In a solution, which is not too strongly acidified with nitric acid, mainly four different nitrosylruthenium complexes are found ${ }^{6}$, namely the trinitrate $(\mathrm{RuT})$, the dinitrate $(\mathrm{RuD})$, the mononitrate $(\mathrm{RuM})$, and a nitrate-free complex (RuN). (Obviously, the complex RuN is not a "nitrato" complex. It is closely related to the others, however, and will therefore be considered in this work). The following formulas have been proposed for these compounds:

$$
\begin{aligned}
& \mathrm{RuT}=\operatorname{RuNO}\left(\mathrm{NO}_{3}\right)_{3}\left(\mathrm{H}_{2} \mathrm{O}\right)_{2} \\
& \mathrm{RuD}=\operatorname{RuNO}\left(\mathrm{NO}_{3}\right)_{2}(\mathrm{OH})\left(\mathrm{H}_{2} \mathrm{O}\right)_{2} \\
& \mathrm{RuM}=\operatorname{RuNO}\left(\mathrm{NO}_{3}\right)(\mathrm{OH})_{2}\left(\mathrm{H}_{2} \mathrm{O}\right)_{2} \\
& \mathrm{RuN}=\operatorname{RuNO}(\mathrm{OH})_{3}\left(\mathrm{H}_{2} \mathrm{O}\right)_{2}
\end{aligned}
$$

These complexes interchange in the following way:

$$
\mathrm{RuT} \underset{k_{\mathrm{DT}}}{\stackrel{k_{\mathrm{TD}}}{\rightleftharpoons}} \mathrm{RuD} \underset{k_{\mathrm{MD}}}{\stackrel{k_{\mathrm{DM}}}{\rightleftharpoons}} \mathrm{RuM} \underset{k_{\mathrm{NM}}}{\stackrel{k_{\mathrm{MN}}}{\rightleftharpoons}} \mathrm{RuN}
$$

The symbols $k_{\mathrm{XY}}$ denote rate constants. The rates of these reactions are all of the first order with respect to ruthenium ${ }^{6}$.

In the present investigation the time for each complete extraction step (1 min) was kept short in comparison to the half-time of the reactions. Thus, it is appropriate to assume that the amount of the complex $\mathrm{X}$ which is converted into the complex $\mathrm{Y}$ during one extraction step is given by the product of its concentration and the "effective" rate constant $k_{\mathrm{XY}}$ (in $\mathrm{min}^{-1}$ ). The actual complex will be found partly in the organic phase and partly in the water phase during the extraction. This is taken into account by using an effective rate constant computed from the partition coefficient and the rate constants in both phases.

Immediately after the $n$ :th extraction the total concentration of nitrosylruthenium nitrates in the water phase and in the organic phase can be written as follows:

$$
\left.\begin{array}{l}
\left(C_{w}\right)_{n}=B_{\mathrm{T} n}\left(1-p_{\mathrm{T}}\right)+B_{\mathrm{D} n}\left(1-p_{\mathrm{D}}\right)+B_{\mathrm{M} n}\left(1-p_{\mathrm{M}}\right)+B_{\mathrm{N} n}\left(1-p_{\mathrm{N}}\right) \\
\left(C_{o}\right)_{n}=B_{\mathrm{T} n} p_{\mathrm{T}}+B_{\mathrm{D} n} p_{\mathrm{D}}+B_{\mathrm{M} n} p_{\mathrm{M}}+B_{\mathrm{N} n} p_{\mathrm{N}}
\end{array}\right\}
$$

Acta Chem. Scand. 13 (1959) No. 8 
Since the actual rate constants are fairly small $\left(<0.1 \mathrm{~min}^{-1}\right)$, all terms which are small of the third or higher orders, i.e. which contain more than two rate constants as factors, are now neglected. The following expressions for the $B_{\mathrm{X} n}$ 's can then be deduced:

$$
\begin{aligned}
& B_{\mathrm{T} n}=c_{\mathrm{T}}\left(1-k_{\mathrm{r}}\right) Q_{\mathrm{T}}{ }^{n-1}+c_{\mathrm{D}} k_{\mathrm{DT}} S_{\mathrm{DT} n}+c_{\mathrm{T}} P_{\mathrm{TDT}} U_{\mathrm{DT} n}+c_{\mathrm{M}} P_{\mathrm{MDT}} V_{\mathrm{MDT} n} \\
& B_{\mathrm{D} n}=c_{\mathrm{D}}\left(1-k_{\mathrm{D}}\right) Q_{\mathrm{D}}{ }^{n-1}+c_{\mathrm{M}} k_{\mathrm{MD}} S_{\mathrm{MD} n}+c_{\mathrm{T}} k_{\mathrm{TD}} S_{\mathrm{TD} n}+c_{\mathrm{D}}\left(P_{\mathrm{DMD}} U_{\mathrm{MD} n}+\right. \\
& \left.+P_{\mathrm{DTD}} U_{\mathrm{TD} n}\right)+c_{\mathrm{N}} P_{\mathrm{NMD}} V_{\mathrm{NMD} n} \\
& B_{\mathrm{M} n}=c_{\mathrm{M}}\left(1-k_{\mathrm{M}}\right) Q_{\mathrm{M}}{ }^{n-1}+c_{\mathrm{N}} k_{\mathrm{NM}} S_{\mathrm{NM} n}+c_{\mathrm{D}} k_{\mathrm{DM}} S_{\mathrm{DM} n}+c_{\mathrm{M}}\left(P_{\mathrm{MNM}} U_{\mathrm{NM} n}+\right. \\
& \left.+P_{\mathrm{MDM}} U_{\mathrm{DM} n}\right)+c_{\mathrm{T}} P_{\mathrm{TDM}} V_{\mathrm{TDM} n} \\
& B_{\mathrm{N} n}=c_{\mathrm{N}}\left(1-k_{\mathrm{N}}\right) Q_{\mathrm{N}}{ }^{n-1}+c_{\mathrm{M}} k_{\mathrm{MN}} S_{\mathrm{MN} n}+c_{\mathrm{N}} P_{\mathrm{NMN}} U_{\mathrm{MN} n}+c_{\mathrm{D}} P_{\mathrm{MDN}} V_{\mathrm{DMN} n}
\end{aligned}
$$

'The concentration symbols $c_{\mathrm{T}}, c_{\mathrm{D}}, c_{\mathrm{M}}$, and $c_{\mathrm{N}}$ appearing in eqns. (7) denote the concentrations of $\mathrm{RuT}, \mathrm{RuD}, \mathrm{RuM}$, and RuN, respectively, at the beginning of the experiment. The other symbols have the following meaning:

$$
\begin{aligned}
& k_{\mathrm{T}}=k_{\mathrm{TD}} ; k_{\mathrm{D}}=k_{\mathrm{DM}}+k_{\mathrm{DT}} ; k_{\mathrm{M}}=k_{\mathrm{MN}}+k_{\mathrm{MD}} ; k_{\mathrm{N}}=k_{\mathrm{NM}} \\
& Q_{\mathrm{X}}=\left(1-k_{\mathrm{X}}\right)\left(1-p_{\mathrm{X}}\right) \\
& P_{\mathrm{XYZ}}=k_{\mathrm{XY}}\left(1-p_{\mathrm{Y}}\right) k_{\mathrm{YZ}} \\
& S_{\mathrm{XY} n}=\frac{Q_{\mathrm{X}}{ }^{n}-Q_{\mathrm{Y}}{ }^{n}}{Q_{\mathrm{X}}-Q_{\mathrm{Y}}} \\
& \mathrm{U}_{\mathrm{XY} n}=\frac{1}{\left(Q_{\mathrm{X}}-Q_{\mathrm{Y}}\right)^{2}}\left[(n-1) Q_{\mathrm{Y}}{ }^{n}-n Q_{\mathrm{Y}}{ }^{n-1} Q_{\mathrm{X}}+Q_{\mathrm{X}}{ }^{n}\right] \\
& V_{\mathrm{XYZn}}=\frac{1}{Q_{\mathrm{X}}-Q_{\mathrm{Y}}}\left[Q_{\mathrm{X}} \frac{Q_{\mathrm{X}}^{n-1}-Q_{\mathrm{Z}}{ }^{n-1}}{Q_{\mathrm{X}}-Q_{\mathrm{Z}}}-Q_{\mathrm{Y}} \frac{Q_{\mathrm{Y}}{ }^{n-1}-Q_{\mathrm{Z}}{ }^{n-1}}{Q_{\mathrm{Y}}-Q_{\mathrm{Z}}}\right]
\end{aligned}
$$

The partition coefficients $q_{\mathrm{M}}$ and $q_{\mathrm{N}}$ are very small $(<0.01)$ for extractions with tributyl phosphate. They will therefore be neglected in this work.

For large values of $n$ both $Q_{\mathrm{T}}{ }^{n}$ and $Q_{\mathrm{D}}{ }^{n}$ become negligible. (At the extraction of $1 \mathrm{M} \mathrm{HNO}$ with $30 \% \mathrm{TBP}$ at $20^{\circ}, Q_{\mathrm{T}}$ is about 0.02 and $Q_{\mathrm{D}}$ about 0.75 .) In this case the following approximation holds:

$$
\begin{aligned}
\left(C_{o}\right)_{n} \rightarrow Q_{\mathrm{M}}{ }^{n}\left[\frac{c_{\mathrm{M}} k_{\mathrm{MD}} p_{\mathrm{D}}}{Q_{\mathrm{M}}-Q_{\mathrm{D}}}+\frac{c_{\mathrm{M}} P_{\mathrm{MDT}} p_{\mathrm{T}}}{\left(Q_{\mathrm{M}}-Q_{\mathrm{D}}\right)\left(Q_{\mathrm{M}}-Q_{\mathrm{T}}\right)}+\frac{c_{\mathrm{D}} P_{\mathrm{DMD}} p_{\mathrm{D}}}{\left(Q_{\mathrm{M}}-Q_{\mathrm{D}}\right)^{2}}-\frac{c_{\mathrm{N}} P_{\mathrm{NMD}} p_{\mathrm{D}}}{\left(Q_{\mathrm{N}}-Q_{\mathrm{M}}\right)\left(Q_{\mathrm{M}}-Q_{\mathrm{D}}\right)}\right]+ & + \\
& +Q_{\mathrm{N}}{ }^{n} \frac{c_{\mathrm{N}} P_{\mathrm{NMD}} p_{\mathrm{D}}}{\left(Q_{\mathrm{N}}-Q_{\mathrm{M}}\right)\left(Q_{\mathrm{N}}-Q_{\mathrm{D}}\right)}
\end{aligned}
$$

The last term in eqn. (8) is usually small. For this reason $\log \left(C_{o}\right)_{n}$ will tend to a straight line when plotted versus $n$. From the slope of this line, $Q_{M}$ is determined. A more accurate value of $Q_{\mathrm{M}}$ can be obtained as a second approximation by taking the last term of eqn. (8) into account. 
For somewhat smaller values of $n,{Q_{\mathrm{T}}}^{n}$ is still negligible but not $Q_{\mathrm{D}}{ }^{n}$. In this case the following difference is obtained by subtracting eqn. (8) (right part) from $\left(C_{o}\right)_{n}:$

$$
\begin{aligned}
& \left(C_{o, d}\right)_{n} \rightarrow Q_{\mathrm{D}}{ }^{n}\left[c_{\mathrm{D}} q_{\mathrm{D}}-\frac{c_{\mathrm{M}} k_{\mathrm{MD}} p_{\mathrm{D}}}{Q_{\mathrm{M}}-Q_{\mathrm{D}}}+\frac{c_{\mathrm{T}} k_{\mathrm{TD}} p_{\mathrm{D}}}{Q_{\mathrm{D}}-Q_{\mathrm{T}}}+\frac{c_{\mathrm{D}} k_{\mathrm{DT}} p_{\mathrm{T}}}{Q_{\mathrm{D}}-Q_{\mathrm{T}}}+\right. \\
& +\frac{c_{\mathrm{N}} P_{\mathrm{NMD}} p_{\mathrm{D}}}{\left(Q_{\mathrm{M}}-Q_{\mathrm{D}}\right)\left(Q_{\mathrm{N}}-Q_{\mathrm{D}}\right)}-\frac{c_{\mathrm{M}} P_{\mathrm{MDT}} p_{\mathrm{T}}}{\left(Q_{\mathrm{M}}-Q_{\mathrm{D}}\right)\left(Q_{\mathrm{D}}-Q_{\mathrm{T}}\right)}+\frac{c_{\mathrm{T}} P_{\mathrm{TDT}} p_{\mathrm{T}}}{\left(Q_{\mathrm{D}}-Q_{\mathrm{T}}\right)^{2}}+ \\
& \left.+\frac{c_{\mathrm{D}} P_{\mathrm{DMD}} p_{\mathrm{D}}}{\left(Q_{\mathrm{M}}-Q_{\mathrm{D}}\right)^{2}}\left(n-1-n \frac{Q_{\mathrm{M}}}{Q_{\mathrm{D}}}\right)+\frac{c_{\mathrm{D}} P_{\mathrm{DTD}} p_{\mathrm{D}}}{\left(Q_{\mathrm{D}}-Q_{\mathrm{T}}\right)^{2}}\left(n-1-n \frac{Q_{\mathrm{T}}}{Q_{\mathrm{D}}}\right)\right]
\end{aligned}
$$

The last two terms within the square brackets are small. Therefore, log $\left(C_{o, d}\right)_{n}$ gives a straight line when plotted versus $n$, and $Q_{\mathrm{D}}$ can be determined from the slope of this line.

By subtraction of the right part of eqn. (9) from $\left(C_{o, d}\right)_{n}$ a new difference is obtained:

$$
\begin{aligned}
\left(\mathrm{C}_{o, d, d}\right)_{n} & =Q_{\mathrm{T}}{ }^{n}\left[c_{\mathrm{T}} q_{\mathrm{T}}-\frac{c_{\mathrm{D}} k_{\mathrm{DT}} p_{\mathrm{T}}+c_{\mathrm{T}} k_{\mathrm{TD}} p_{\mathrm{D}}}{Q_{\mathrm{D}}-Q_{\mathrm{T}}}+\right. \\
& + \text { smaller terms }] .
\end{aligned}
$$

If $\log \left(C_{o, d, d}\right)_{n}$ is plotted versus $n$ a straight line is obtained with the slope equal to $\log Q_{\mathrm{T}}$. The line is very steep, however, and it is better to determine $Q_{\mathrm{T}}$ by other experiments (repeated extractions of an organic phase).

As an illustration $C_{o}, C_{o, d}$ and $C_{o, d, d}$ have been plotted versus $n$ on a semilogarithmic scale in Fig. 1.

If the partition coefficients and the rate constants are known, eqn. (10) can be used for a determination of $c_{\mathrm{T}}$ (the term containing $c_{\mathrm{D}}$ is very small and can be neglected).

$$
c_{\mathrm{T}}=\frac{\left(C_{o, d, d}\right)_{n=1}}{Q_{\mathrm{T}}\left[q_{\mathrm{T}}-\frac{k_{\mathrm{TD}} p_{\mathrm{D}}}{Q_{\mathrm{D}}-Q_{\mathrm{T}}}\right]}
$$

For the determination of the relative concentrations $c_{\mathrm{D}}, c_{\mathrm{M}}$ and $c_{\mathrm{N}}$ the following relationships are chosen: (a) the value $A_{\mathrm{o}}$ of the right part of eqn. (9) for $n$ equal to zero as determined by extrapolation of the straight line, and (b) the ratio $\left(C_{o}\right)_{n} /\left(C_{w}\right)_{n}=q_{n}$ for a large value of $n$ (the value $n=25$ was used). The former relationship depends essentially on the concentration of the dinitrate and the latter on the ratio between the concentrations of the mononitrate and the nitrate-free complex. Besides, all concentrations add up to unity so that a system of equations of the following type is obtained:

$$
\left.\begin{array}{ll} 
& c_{\mathrm{N}}+c_{\mathrm{M}}+c_{\mathrm{D}}=1-c_{\mathrm{T}} \\
\text { (a) } \alpha_{1} c_{\mathrm{N}}+\alpha_{2} c_{\mathrm{M}}+\alpha_{3} c_{\mathrm{D}}=A_{\mathrm{o}}-\alpha_{4} c_{\mathrm{T}} \\
\text { (b) }\left(\beta_{1}-q_{n} \gamma_{1}\right) c_{\mathrm{N}}+\left(\beta_{2}-q_{n} \gamma_{2}\right) c_{\mathrm{M}}+\left(\beta_{3}-q_{n} \gamma_{3}\right) c_{\mathrm{D}}=\left(q_{n} \gamma_{4}-\beta_{4}\right) c_{\mathrm{T}}
\end{array}\right\}
$$

Acta Chem. Scand. 13 (1959) No. 8 


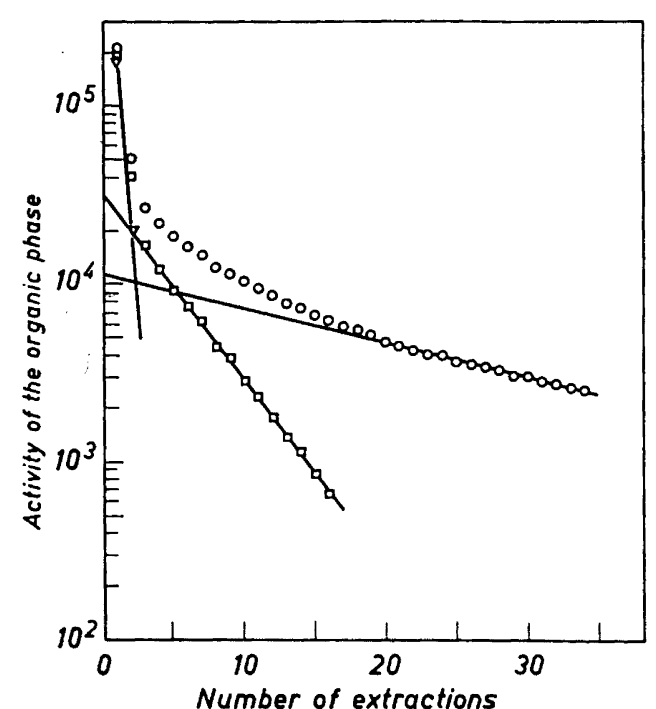

Fig. 1. The activity (proportional to the total concentration of nitrosylruthenium nitrates) of the organic phase versus the number of extractions for repeated extractions of a water phase. Circles: $\left(C_{o}\right)_{n}$;

Squares: $\left(C_{o, d}\right)_{n}$; Triangles: $\left(C_{o, d, d}\right)_{n}$.

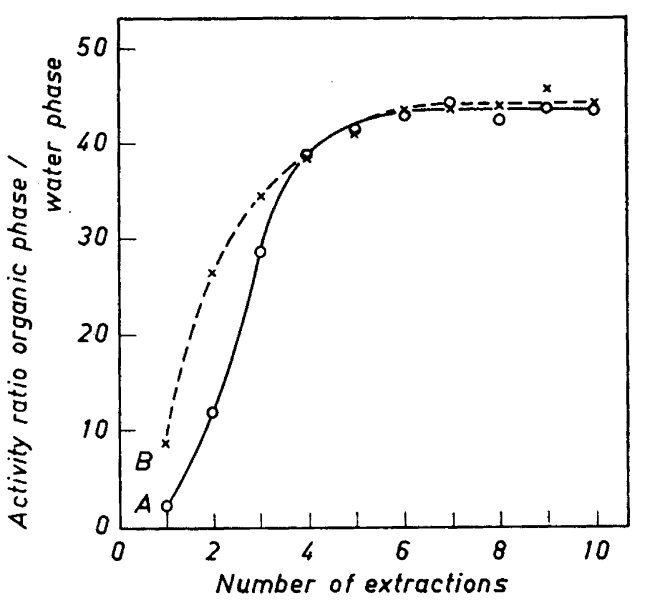

Fig. 2. The ratio between the activity of the organic phase and that of the water phase versus the number of extractions for repeated extractions of an organic phase. Curve A: The activity was originally in the water phase. Curve B: The activity was originally in the organic phase.

The $\alpha$ 's, $\beta$ 's and $\gamma$ 's depend only on the partition coefficients and the rate constants. They are easily calculated from eqns. (6), (7), and (9). The expressions are somewhat lengthy, however, and they are therefore not written out here.

Repeatedextractions of anorganic phasecontaining dependent constituents (nitrosylruthenium nitrates)

For repeated extractions of an organic phase eqns. (6) and (7) are valid if the factor $\left(1-p_{\mathrm{X}}\right)$ is changed into $p_{\mathrm{X}}$ in the expressions for $Q_{\mathrm{X}}$ and $P_{\mathrm{XYz}}$. Thus

$$
\begin{aligned}
& Q_{\mathrm{X}}^{\prime}=p_{\mathrm{X}}\left(1-k_{\mathrm{X}}^{\prime}\right) \\
& P_{\mathrm{XYZ}}^{\prime}=k_{\mathrm{XY}}^{\prime} p_{\mathrm{Y}} k_{\mathrm{YZ}}^{\prime}
\end{aligned}
$$

The rate constants, which appear here, differ from the corresponding ones in the preceeding section. Since they turn out to be considerably smaller, terms which are small of the second order, $i$. e. terms containing $P_{\mathrm{XYz}}^{\prime}$ as a factor, can be neglected. Besides, $Q_{\mathrm{N}}^{\prime}$ and $Q_{\mathrm{M}}^{\prime}$ are negligible. 
For large values of $n, Q_{\mathrm{D}}^{\prime}{ }^{n}$ can be neglected, and the following relation is obtained:

with

$$
\frac{\left(C_{o}^{\prime}\right)_{n}}{\left(C_{w}^{\prime}\right)_{n}} \rightarrow q_{\mathrm{T}}(1-\delta)
$$

$$
\delta \sim \frac{k_{\mathrm{T}_{\mathrm{D}}}^{\prime}}{Q_{\mathrm{T}}^{\prime}-Q_{\mathrm{D}}^{\prime}}\left[q_{\mathrm{T}}\left(1-p_{\mathrm{D}}\right)-p_{\mathrm{D}}\right]
$$

From eqn. (13) $q_{\mathrm{T}}$ is determined by successive approximations.

The ratio $\left(C_{o}^{\prime}\right)_{n} /\left(C_{w}^{\prime}\right)_{n}$ has been plotted versus $n$ in Fig. 2 . It tends to become a constant after $4-5$ extractions.

For large values of $n,\left(C_{o}^{\prime}\right)_{n}$ can be written:

$$
\left(C_{o}^{\prime}\right)_{n} \rightarrow c_{\mathrm{T}} Q_{\mathrm{T}}^{\prime}{ }^{n}(1+\varepsilon)
$$

with

$$
\varepsilon \sim \frac{p_{\mathrm{T}}\left[k_{\mathrm{TD}}^{\prime} \frac{p_{\mathrm{D}}}{p_{\mathrm{T}}}+k_{\mathrm{DT}}^{\prime} \frac{c_{\mathrm{D}}}{c_{\mathrm{T}}}\right]}{Q_{\mathrm{T}}^{\prime}-Q_{\mathrm{D}}^{\prime}}
$$

The right part of eqn. (14) corresponds to a straight line when plotted versus $n$ on a semilogarithmic scale. The intercept for $n$ equal to zero can be used for a determination of $c_{\mathrm{T}}$.

If $\log \left(C_{w}^{\prime}\right)_{n}$ is plotted versus $n$, a straight line is obtained for large values of $n$. By a subtraction procedure similar to the one leading to $\left(C_{o, d}\right)_{n}$ (eqn. (9)), the following difference results:

$$
\left(C_{w, d}\right)_{n}=Q_{\mathrm{D}}^{\prime} n\left[\frac{c_{\mathrm{D}}}{q_{\mathrm{D}}}+\frac{c_{\mathrm{M}} k_{\mathrm{MD}}^{\prime}}{q_{\mathrm{D}}\left(1-k_{\mathrm{D}}^{\prime}\right)}-\frac{c_{\mathrm{T}} k_{\mathrm{TD}}^{\prime}\left(1-p_{\mathrm{D}}\right)+c_{\mathrm{D}} k_{\mathrm{DT}}^{\prime}\left(1-p_{\mathrm{T}}\right)}{Q_{\mathrm{T}}^{\prime}-Q_{\mathrm{D}}^{\prime}}\right]
$$

A straight line results when $\log \left(C_{w, d}^{\prime}\right)_{n}$ is plotted as a function of $n$. The line has the slope $\log Q_{\mathrm{D}}^{\prime}$ and can be used for a determination of $Q_{\mathrm{D}}^{\prime}$. An approximate value of $c_{\mathrm{D}}$ is also obtained.

The accuracy of the determinations. The reproducibility of the determinations is high, especially with regard to $\mathrm{RuT}$. Thus it is possible to determine $c_{\mathrm{T}}$ with an accuracy of better than $1 \%$, and the $q_{\mathrm{T}}$-values are in many cases accurate to $\pm 2 \%$. The determinations of $q_{\mathrm{D}}$ are reliable to $\pm 5-10 \%$.

The accuracy of the determinations of $c_{\mathrm{D}}, c_{\mathrm{M}}$, and $c_{\mathrm{N}}$ depends essentially upon how well the rate constants are determined. It is probably not better than $\pm 10-20 \%$.

\section{EXPERIMENTAL}

Solutions. The nitrosylruthenium nitrate contained tracer of ${ }^{106} \mathrm{Ru}$. A stock solution in $8 \mathrm{M}$ nitric acid was prepared as described in Ref. ${ }^{6}$. The stock solution was carrierfree. An analysis was performed using the dithio-oxamide method ${ }^{10}$ after the distilla-

Acta Chem. Scand. 13 (1959) No. 8 
tion of ruthenium as the tetroxide. The analysis showed that the ruthenium concentration of the samples was less than $10^{-7} \mathrm{M}$.

The tri-n-butyl phosphate was first washed with a $5 \%$ solution of sodium carbonate and then distilled at vacuum. After the distillation it was diluted with an inert mixture of hydrocarbons.* The concentration of tributyl phosphate was determined analytically by the method of Allen and DeSesa ${ }^{11}$.

The experimental procedure. Repeated extractions of a water phase were carried out using an extraction apparatus (Fig. 3) where the lighter organic phase could be easily removed after each extraction. The extractions were performed by stirring for 30 sec. After this, the phases were separated and a new portion of tributyl phosphate was added. The time allowed for this was also 30 sec. so that the time interval between two successive extractions was exactly $1 \mathrm{~min}$. The experiment was usually carried out at $20^{\circ}$ with $0.95 \mathrm{M}$ nitric acid as the water phase and $30 \%$ tributyl phosphate as the organic phase. The volume of each phase was $5 \mathrm{ml}$, and the number of extractions was $25-35$. The activities of all organic phases and the water phase were measured with a scintillation counter. The activity was used as a measure of the concentration.

At the experiments with repeated extractions of an organic phase, a separation funnel was used. The number of extractions was 10 .

The acidity of the water phases was determined by titration after the extractions.

\section{RESULTS}

\section{Dependence on the extraction time}

In a series of experiments with repeated extractions of an organic phase (30\% TBP) with $1 \mathrm{M}$ nitric acid at $20^{\circ}$, the extraction time was varied. The partition coefficients obtained are tabulated in Table 1.

* Nysolvin 160/200, a mainly paraffinic kerosene fraction from Nynäs-Petroleum AB.

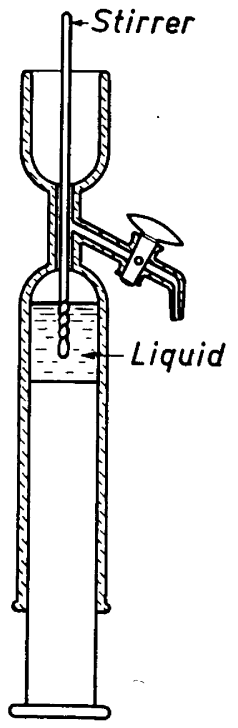

Fig. 3. Extraction apparatus for repeated extractions of the heavier phase.

Acta Chem. Scand. 13 (1959) No. 8 
Table 1. The dependence of the partition coefficients on the extraction time.

\begin{tabular}{|c|c|c|}
\hline $\begin{array}{c}\text { Extraction } \\
\text { time }\end{array}$ & $q_{\mathrm{T}}$ & $q_{\mathrm{D}}$ \\
\hline 15 sec. & 46.9 & 0.28 \\
$30 "$ & 47.9 & 0.28 \\
$40 "$ & 47.4 & 0.32 \\
\hline
\end{tabular}

The partition coefficients are independent of the extraction time in the interval studied. Thus stirring for $30 \mathrm{sec}$ is adequate for the equilibrium between the phases to be reached. Similar results regarding RuT have been obtained by Brown et al. ${ }^{6}$

Studies on the kinetics of the interchange between the nitrosylruthenium nitrates

(a) Rate constants in $0.95 \mathrm{M}$ nitric acid. In order to make a determination of partition coefficients and concentrations from the extraction data possible, the rate constants must be known. Kinetic experiments are therefore essential. Since the analyses by the method of repeated extractions were usually carried out at $20^{\circ}$ and with the system $0.95 \mathrm{M} \mathrm{HNO}_{3}-30 \% \mathrm{TBP}$, it was of primary interest to determine the rate constants corresponding to these conditions.

In a series of experiments a pure solution of RuT in $30 \%$ tributyl phosphate was first prepared by removing all other complexes by repeated extractions with $1 \mathrm{M}$ nitric acid. The trinitrate was then reextracted into $8 \mathrm{M}$ nitric acid, and the solution was diluted to $0.95 \mathrm{M}$ with water. It was kept at $20^{\circ}$ in a thermostate. Samples were taken at different times for repeated extractions, and the quantities $\left(C_{o, d, d}\right)_{n=1}, A_{o}$, and $q_{25}$ (eqns. (11) and (12)) were measured.

Starting from the approximations $k_{\mathrm{TD}}=k_{\mathrm{NM}}=0$ and $Q_{\mathrm{M}}=1-k_{\mathrm{MD}}$, the constants of eqns. (12) were calculated and the concentrations determined. Next, new rate constants were determined from the concentrations just obtained. The kinetic equations are of the following form:

$$
\left.\begin{array}{l}
\frac{\mathrm{d} c_{\mathrm{T}}}{\mathrm{d} t}=-k_{\mathrm{TD}} c_{\mathrm{T}}+k_{\mathrm{DT}} c_{\mathrm{D}} \\
\frac{\mathrm{d} c_{\mathrm{N}}}{\mathrm{d} t}=-k_{\mathrm{NM}} c_{\mathrm{N}}+k_{\mathrm{MN}} c_{\mathrm{M}}
\end{array}\right\}
$$

Now, $k_{\mathrm{DT}}$ can be expressed in $k_{\mathrm{TD}}$ and $k_{\mathrm{MN}}$ in $k_{\mathrm{NM}}$ using the concentrations at equilibrium. The derivatives in eqns. (16) are then replaced by the differences $\frac{\Delta c_{\mathrm{T}}}{\Delta t}$ and $\frac{\Delta c_{\mathrm{N}}}{\Delta t}$, and the rate constants $k_{\mathrm{TD}}$ and $k_{\mathrm{NM}}$ are determined graphically. They are combined with the relation $Q_{\mathrm{M}}=1-k_{\mathrm{M}}$ and all equilibrium concentrations to yield the remaining rate constants, and the "effective" rate con-

Acta Chem. Scand. 13 (1959) No. 8 
stants are calculated. These are used for new determinations of the concentrations $c_{\mathrm{x}}$. By successive approximations, values of $c_{\mathrm{x}}$ and $k_{\mathrm{xy}}$ are finally found which are not changed by further approximations. The final values of the rate constants in $0.95 \mathrm{M}$ nitric acid and at the temperature $20^{\circ}$ are tabulated in Table 2.

Table 2. Rate constants in $0.95 \mathrm{M} \mathrm{HNO}_{3}$.

\begin{tabular}{|l|lc|}
\hline$k_{\mathrm{M}}$ & 0.051 & $\mathrm{~min}^{-1 *}$ \\
$k_{\mathrm{TD}}$ & 0.025 & $"$ \\
$k_{\mathrm{DT}}$ & 0.0024 & $\prime$ \\
$k_{\mathrm{DM}}$ & 0.084 & $" 1$ \\
$k_{\mathrm{MD}}$ & 0.047 & $"$ \\
$k_{\mathrm{MN}}$ & 0.0041 & $"$ \\
$k_{\mathrm{MM}}$ & 0.0025 & $"$ \\
\hline
\end{tabular}

* This value was obtained from $Q_{M}=0.949 \pm 0.002$, average of 34 determinations.

The following value of $Q_{\mathrm{D}}$ (average of 34 determinations) has been obtained:

$$
Q_{\mathrm{D}}=\left(1-k_{\mathrm{D}}\right)\left(1-p_{\mathrm{D}}\right)=0.742 \pm 0.007
$$

The effective value of $k_{\mathrm{D}}$ is found to be $0.078 \mathrm{~min}^{-1}$ from the appropriate rate constants in $0.95 \mathrm{M}$ nitric acid and tributyl phosphate. With this $k_{\mathrm{D}}$-value one obtains

$$
p_{\mathrm{D}}=0.195 ; q_{\mathrm{D}}=0.242
$$

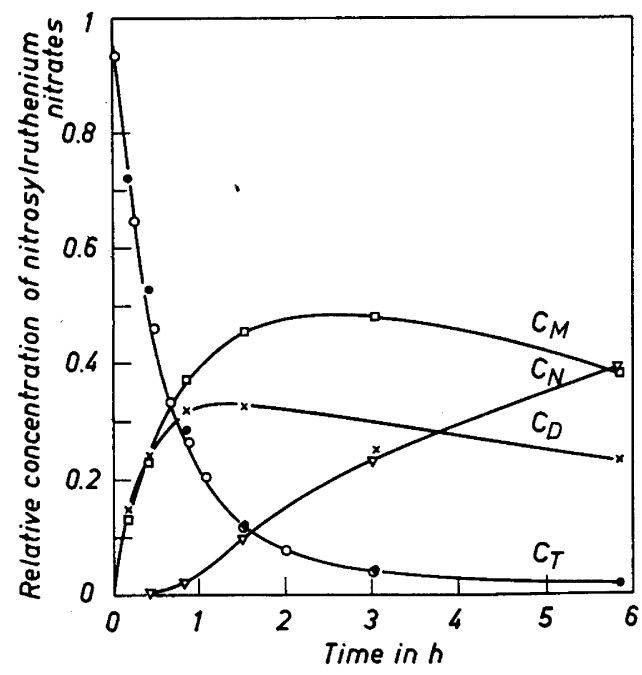

Fig. 4. Relative concentrations of nitrosylruthenium nitrates versus time starting from a solution of pure RuT in $0.95 \mathrm{M}$ nitric acid. Temperature: $20^{\circ}$.

Filled circles: $c_{\mathrm{T}}$

Crosses: $c_{\mathrm{D}}$

Squares: $c_{M}$

Triangles: $c_{\mathrm{N}}$

Open circles: $c r$
From repeated extractions of a water phase.

From repeated extractions of an organic phase. 


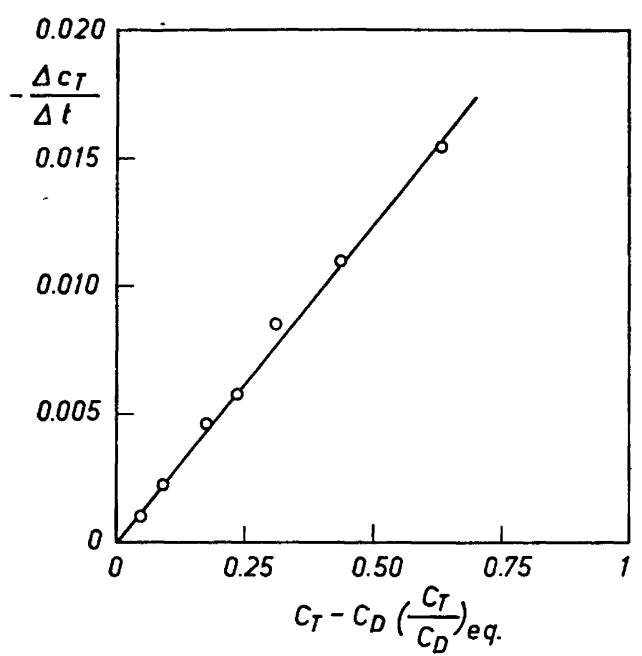

Fig. 5. $\frac{\Delta c_{\mathrm{T}}}{\Delta t}$ versus $c_{\mathrm{T}}-c_{\mathrm{D}}\left(\frac{c_{\mathrm{T}}}{c_{\mathrm{D}}}\right)_{\text {eq. }}$ for RuT in $0.95 \mathrm{M}$ nitric acid. Temperature: $20^{\circ}$.

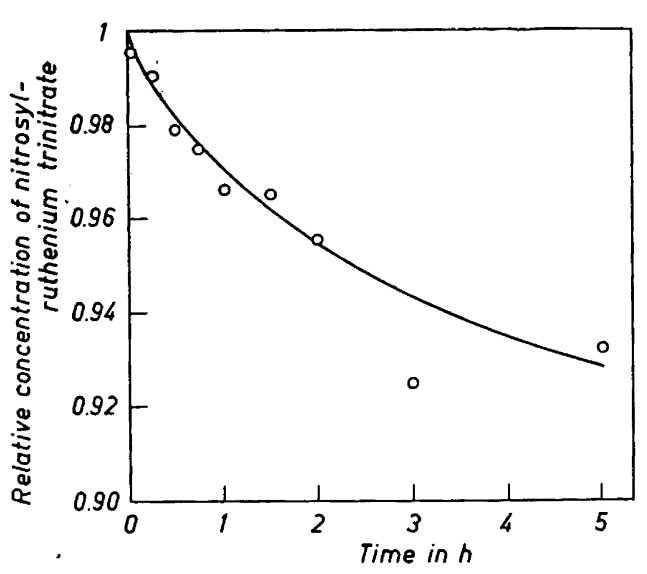

Fig. 6. Relative concentration of RuT versus time starting from a solution of pure RuT in $30 \%$ tributyl phosphate. Temperature: $20^{\circ}$.

The concentrations of the nitrosylruthenium nitrates in $0.95 \mathrm{M}$ nitric acid are plotted versus time in Fig. 4.

As an example of the rate constant analyses, $\frac{\Delta c_{\mathrm{T}}}{\Delta t}$ has been plotted versus $c_{\mathrm{T}}-c_{\mathrm{D}}\left(\frac{c_{\mathrm{T}}}{c_{\mathrm{D}}}\right)_{\text {eq. }}$ in Fig. 5. The slope of the straight line corresponds to $k_{\mathrm{TD}}$. The value $0.025 \mathrm{~min}^{-1}$ is found.

(b) Rate constants in $30 \%$ tributyl phosphate saturated with $0.95 \mathrm{M}$ nitric acid. The decrease of $c_{\mathrm{T}}$ in a solution of RuT in $30 \%$ tributyl phosphate (saturated with $0.95 \mathrm{M}$ nitric acid) has also been studied. The temperature was $20^{\circ}$. In this case only two components have to be considered, namely RuT and RuD. The following rate constants were obtained:

$$
\begin{aligned}
& k_{\mathrm{TD}, o}=0.00067 \mathrm{~min}^{-1} \\
& k_{\mathrm{DT}, o}=0.0059 \mathrm{~min}^{-1}
\end{aligned}
$$

Fig. 6 shows $c_{\mathrm{T}}$ as a function of time.

A conversion of the aquo-complexed nitrosylruthenium trinitrate into the corresponding TBP-complexed compound has been proposed to occur in tributyl phosphate solutions ${ }^{6}$. The latter compound is thought to have a much higher partition coefficient $\left(>10^{3}\right)$ than the former. The half-time of the reaction is estimated to be about $3 \mathrm{~min}$ and that of the reverse reaction to be about $6 \mathrm{~min}$. In this work a great number of experiments with repeated extractions of organic phases have been performed in which the ruthenium was originally in the water phase. The experiments cover the temperature range

Acta Chem. Scand. 13 (1959) No. 8 
$0^{\circ}-50^{\circ}$ and the acidity range $0.165 \mathrm{M}-3.25 \mathrm{M}$ (water phase). In all these experiments results similar to those in Fig. 2 were found. The activity ratio reaches a constant value after 4-5 extractions, $i$. $e$. after $4-5 \mathrm{~min}$. The same results were obtained also in experiments where the ruthenium was originally in the TBP-phase, in some cases for as long as 18 days. This is not in accord with the hypothesis mentioned above. The conversion proposed would cause the activity ratio to approach a constant value much more slowly. On the other hand, it is quite possible that a more rapid interchange takes place. If this is the case, a measured $q_{\mathrm{T}}$-value will be a function of the true partition coefficient of the aquo-complex and the rate constants of the interchange.

(c) The temperature dependence of the rate constants in $0.95 \mathrm{M}$ nitric acid. Kinetic experiments have been carried out at three different temperatures: $10^{\circ}, 20^{\circ}$, and $30^{\circ}$. The nitric acid concentration of the solutions was $0.95 \mathrm{M}$. The results are given in Table 3 and shown in Fig. 7.

Table 3. The temperature dependence of the rate constants.

\begin{tabular}{|c|l|l|l|l|}
\hline Temperature & $k_{\mathrm{TD}}, \mathrm{min}^{-1}$ & $k_{\mathrm{DT}}, \mathrm{min}^{-1}$ & $k_{\mathrm{MN}}, \mathrm{min}^{-1}$ & $k_{\mathrm{NM}}, \mathrm{min}^{-1}$ \\
\hline $10^{\circ}$ & 0.0065 & 0.00096 & & \\
$20^{\circ}$ & 0.025 & 0.0024 & 0.0041 & 0.0025 \\
$30^{\circ}$ & 0.068 & 0.0058 & 0.012 & 0.0085 \\
\hline
\end{tabular}

An increase of the temperature by $10^{\circ}$ corresponds to a threefold increase of the rate constants. Jenkins and Wain ${ }^{5}$ have carried out a series of rate constant determinations. Their results for the rate constant $k_{\mathrm{TD}}$ in $0.7-0.8 \mathrm{M}$ nitric acid obtained at $0^{\circ}, 25^{\circ}$, and $35^{\circ}$ have also been plotted in Fig. 7 .

(d) The acidity dependence of the rate constants. The dependence of the rate constants on the acidity of the water phase has been studied at the temperature $20^{\circ}$. The results are given in Table 4 and shown in Fig. 8.

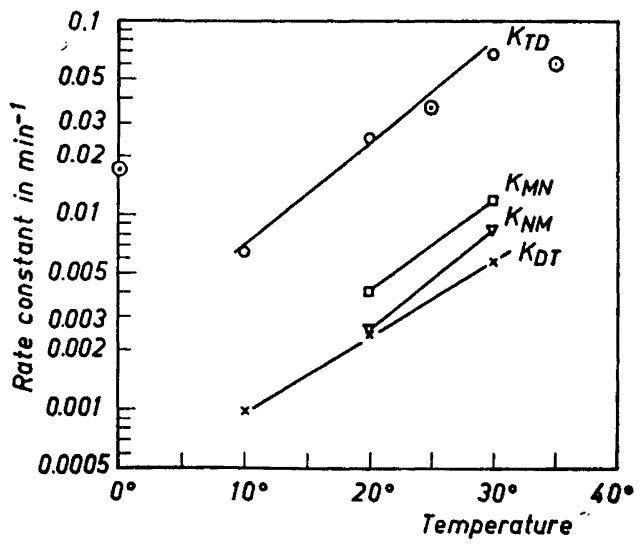

Fig. 7. The temperature dependence of the rate constants in $0.95 \mathrm{M}$ nitric acid. Circles: $k_{\mathrm{TD}}$; Crosses: $k_{\mathrm{DT}}$; Squares: $k_{\mathrm{MN}}$; Triangles: kNM; Dotted circles: $k_{\mathrm{TD}}$ from Ref. 
Table 4. The acidity dependence of the rate constants.

\begin{tabular}{|c|c|c|c|c|}
\hline Acidity & $k_{\mathrm{TD}}, \mathrm{min}^{-1}$ & $k_{\mathrm{DT}}, \mathrm{min}^{-1}$ & $k_{\mathrm{MN}}, \mathrm{min}^{-1}$ & $k_{\mathrm{NM}}, \mathrm{min}^{-1}$ \\
\hline $0.95 \mathrm{M}$ & 0.025 & 0.0024 & 0.0041 & 0.0025 \\
$1.92 \mathrm{M}$ & 0.019 & 0.0058 & 0.0046 & 0.014 \\
$3.80 \mathrm{M}$ & 0.018 & 0.013 & & \\
$7.11 \mathrm{M}$ & 0.020 & 0.053 & & \\
\hline
\end{tabular}

The rate constant $k_{\text {TD }}$ is almost independent of the acidity. This is in agreement with the results by Jenkins and Wain ${ }^{5}$.

In Fig. $9 c_{\mathrm{T}}$ has been plotted versus time for different acidities.

Relative concentrations of thenitrosylruthenium complexes at equilibrium in aqueous nitric acid solutions

A series of nitrosylruthenium solutions of varying nitric acid concentration were prepared and analysed after about one week by repeated extractions of an organic phase (determination of $c_{\mathrm{T}}$ and $c_{\mathrm{D}}$ ) or repeated extractions of a water phase (determination of $c_{\mathrm{T}}, c_{\mathrm{D}}, c_{\mathrm{M}}$, and $c_{\mathrm{N}}$ ). The results are tabulated in Tables 5 and 6 , respectively, and plotted versus the acidity in Fig. 10.

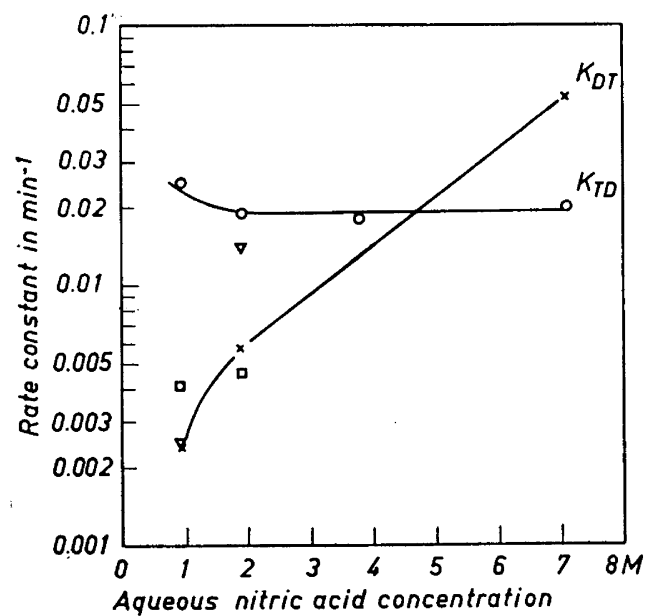

Fig. 8. The acidity dependence of the rate constants. Temperature: $20^{\circ}$. Circles: $k_{\mathrm{TD}}$; Crosses: $k_{\mathrm{DT}}$; Squares: $k_{\mathrm{MN}}$; Triangles: $k \mathrm{NM}$.

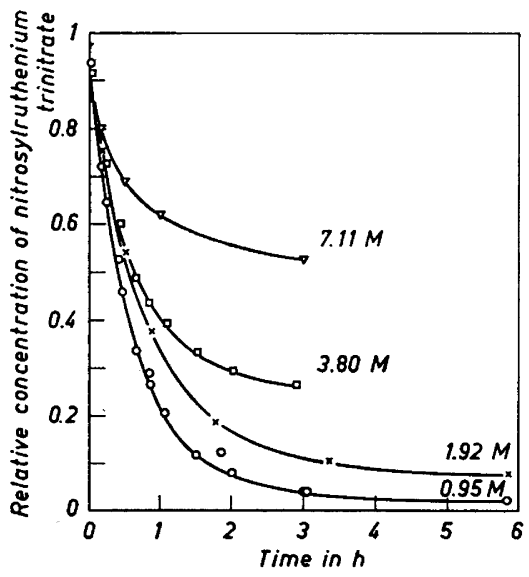

Fig. 9. Relative concentration of RuT versus time starting from a solution of pure RuT in aqueous nitric acid. Temperature: $20^{\circ}$. Circles: $0.95 \mathrm{M} \mathrm{HNO}_{3}$; Crosses: $1.92 \mathrm{M}$ $\mathrm{HNO}_{3}$; Squares: $3.80 \mathrm{M} \mathrm{HNO}$; Triangles: $7.11 \mathrm{M} \mathrm{HNO}_{3}$.

Acta Chem. Scand. 13 (1959) No. 8 
Table 5. Relative concentrations of nitrosylruthenium nitrates.

\begin{tabular}{|c|c|c|}
\hline Acidity, $\mathrm{M}$ & $c_{\mathrm{D}}$ & $c_{\mathrm{T}}$ \\
\hline 0.316 & 0.00305 & 0.16 \\
0.517 & 0.00655 & 0.21 \\
0.747 & 0.0115 & 0.18 \\
1.37 & 0.0288 & 0.22 \\
2.03 & 0.0611 & 0.27 \\
2.73 & 0.109 & 0.26 \\
3.31 & 0.154 & \\
3.64 & 0.182 & \\
4.13 & 0.232 & \\
5.54 & 0.383 & \\
6.61 & 0.481 & \\
8.15 & 0.640 & \\
10.2 & 0.785 & \\
12.4 & 0.882 & \\
13.5 & 0.923 & \\
\hline
\end{tabular}

Table 6. Relative concentrations of nitrosylruthenium nitrates.

\begin{tabular}{|c|l|l|l|l|}
\hline Acidity, M & $c_{\mathrm{T}}$ & $c_{\mathrm{D}}$ & $c_{\mathrm{M}}$ & $c_{\mathrm{N}}$ \\
\hline 0.316 & 0.0028 & 0.076 & 0.20 & 0.72 \\
0.506 & 0.0069 & 0.13 & 0.29 & 0.58 \\
1.01 & 0.025 & 0.19 & 0.31 & 0.48 \\
1.94 & 0.063 & 0.24 & 0.36 & 0.33 \\
2.84 & 0.124 & 0.27 & 0.41 & 0.20 \\
4.63 & 0.269 & 0.28 & 0.37 & 0.077 \\
5.96 & 0.417 & 0.24 & 0.30 & 0.037 \\
8.15 & 0.582 & 0.16 & 0.24 & 0.014 \\
10.3 & 0.709 & 0.11 & 0.18 & 0 \\
12.4 & 0.757 & 0.084 & 0.16 & 0 \\
\hline
\end{tabular}

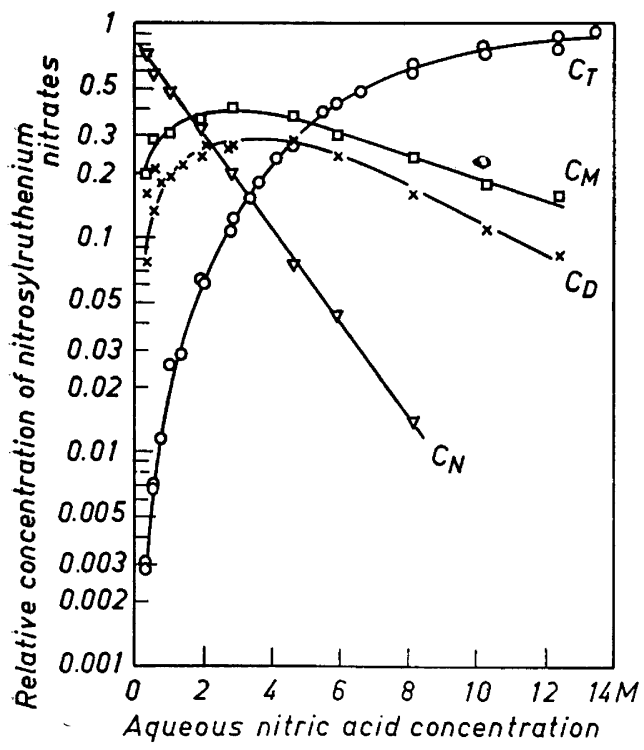

Fig. 10. The concentrations at equilibrium of nitrosylruthenium nitrates in aqueous nitric acid versus the acidity. Circles: $c_{\mathrm{T}}$; Crosses: $c_{\mathrm{D}}$; Squares: $c_{\mathrm{M}}$; Triangles: $c_{\mathbf{N}}$.

Acta Chem. Scand. 13 (1959) No. 8 
Studies on the partition coefficients of the nitrosylruthenium nitrates

(a) Dependence on the tributyl phosphate concentration. Tributyl phosphate solutions with the concentration varying from $10 \%$ to $50 \%$ were extracted at $20^{\circ}$ with I M nitric acid. The measured partition coefficients are tabulated in Table 7 and plotted versus the tributyl phosphate concentration in Fig. 11.

Table \%. Partition coefficients for different concentrations of tributyl phosphate.

\begin{tabular}{|c|c|c|}
\hline $\begin{array}{c}\text { Concentration of } \\
\text { TBP, \% }\end{array}$ & $q_{\mathrm{T}}$ & $q_{\mathrm{D}}$ \\
\hline & 2.4 & \\
10.0 & 8.5 & 0.13 \\
15.6 & 19.5 & 0.18 \\
21.0 & 33.2 & 0.23 \\
35.9 & 45.1 & 0.39 \\
36.1 & 67.5 & 0.56 \\
40.9 & 113 & 0.54 \\
45.4 & 150 & 0.52 \\
50.0 & & 0.63 \\
\hline
\end{tabular}

As found by other investigators ${ }^{6}$ a plot of $\log q_{\mathrm{T}}$ versus $\log C_{\mathrm{TBP}}$ gives a straight line with the slope about 2 (the value 2.3 is obtained from Fig. 11).

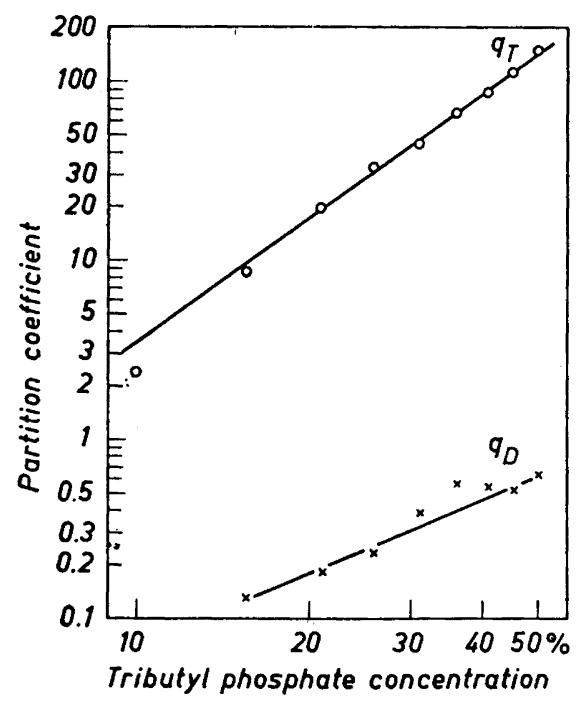

Fig. 11. The dependence of the partition coefficients on the tributyl phosphate concentration fo $i$ extractions with $1 \mathrm{M}$ nitric acid. Temperature: $20^{\circ}$. Circles: $q_{\mathrm{T}}$; Crosses: $q_{\mathrm{D}}$.

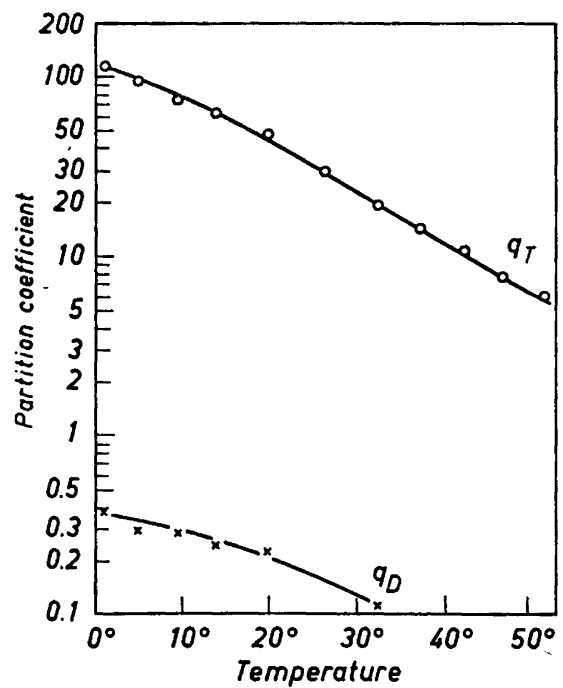

Fig. 12. The temperature dependence of the partition coefficients for $3 x$ tractions of $1 \mathrm{M}$ nitric acid with $30 \%$ tributyl phosphate. Circles: $q_{\mathrm{T}}$; Crosses: $q_{\mathrm{D}}$. 
(b) Dependence on the temperature. The partition coefficients $q_{\mathrm{T}}$ and $q_{\mathrm{D}}$ were determined in experiments with repeated extractions of organic phases (30\% TBP) with $1 \mathrm{M}$ nitric acid at different temperatures. Eqn. (13) was used for the evaluation of $q_{\mathrm{r}}$. The effective rate constant $k_{\mathrm{TD}}^{\prime}$, which forms part of the correction factor $\delta$, contains $k_{\mathrm{TD}, w}$ and $k_{\mathrm{TD}, o}$. The temperature dependence of $k_{\mathrm{TD}, w}$ is obtained from Fig. 7. Only one $k_{\mathrm{TD}, o}$-value has been determined, namely that for $20^{\circ}$. The temperature dependence is assumed to be the same as for $k_{\mathrm{TD}, w}, i$.e a temperature increase of $10^{\circ}$ corresponds to a threefold increase of $k_{\mathrm{TD}, \mathrm{o}}$.

For the determination of $q_{\mathrm{D}}$ from the experimental values of $Q_{\mathrm{D}}^{\prime}=$ $p_{\mathrm{D}}\left(1-k_{\mathrm{D}}^{\prime}\right)$, the effective rate constant $k_{\mathrm{D}}^{\prime}$ must be known. This contains $k_{\mathrm{DT}, w}$, $k_{\mathrm{DT}, o}$, and $k_{\mathrm{DM}, w}$. The first of these three rate constants is obtained from Fig. 7. The others are assumed to vary with temperature in the same way as $k_{\mathrm{TD}, w}$. Their values at $20^{\circ}$ are known.

The resulting determinations of $q_{\mathrm{T}}$ and $q_{\mathrm{D}}$ are tabulated in Table 8 and plotted versus temperature in Fig. 12.

Table 8. The temperature dependence of the partition coefficients.

\begin{tabular}{|c|c|c|}
\hline Temperature, ${ }^{\circ} \mathrm{C}$ & $q_{\mathrm{T}}$ & $q_{\mathrm{D}}$ \\
\hline 1.0 & 116 & 0.37 \\
5.0 & 94 & 0.29 \\
9.6 & 75 & 0.28 \\
14.0 & 63 & 0.24 \\
20.0 & 48.1 & 0.22 \\
26.5 & 29.6 & 0.10 \\
32.6 & 19.2 & 0.11 \\
37.6 & 14.4 & \\
42.8 & 10.9 & \\
47.2 & 7.6 & \\
52.0 & 6 & \\
\hline
\end{tabular}

Table 9. The acidity dependence of the partition coefficients.

\begin{tabular}{|c|r|c|}
\hline Acidity, M & $q_{\mathrm{T}}$ & $q_{\mathrm{D}}$ \\
\hline 0.165 & 120 & 0.27 \\
0.326 & 102 & 0.24 \\
0.506 & 94 & 0.35 \\
0.817 & 62 & 0.30 \\
0.937 & 45 & 0.19 \\
1.00 & 39 & \\
1.01 & 38 & \\
1.22 & 27.5 & \\
1.62 & 16.7 & \\
2.06 & 7.3 & \\
2.37 & 3.0 & \\
2.79 & 2.7 & \\
3.25 & 2.0 & \\
\hline
\end{tabular}


(c) Dependence on the acidity of the water phase. The acidity dependence of the partition coefficients was studied using two different methods for both $q_{\mathrm{T}}$ and $q_{\mathrm{D}}$. First repeated extractions of an organic phase (30\% TBP) were carried out at the temperature $20^{\circ}$ with water phases of the desired acidity. The results are tabulated in Table 9.

In the second method for the determination of $q_{\mathrm{T}}$, a pure solution of the trinitrate in $30 \%$ tributyl phosphate was prepared by $8-10$ extractions with $1 \mathrm{M}$ nitric acid. The organic solution was then extracted at $20^{\circ}$ with nitric acid of the desired strength (the acidity was measured after the experiment), and the partition coefficient was determined from the ratio between the activities in the phases after a correction for the formation of dinitrate during the experiment. The results are given in Table 10 .

Table 10. The acidity dependence of $q_{\mathrm{T}}$.

\begin{tabular}{|c|c|}
\hline Acidity, M. & $q_{\mathrm{T}}$ \\
\hline 0.0003 & 24.5 \\
0.0040 & 63 \\
0.456 & 92 \\
0.691 & 79 \\
0.815 & 66 \\
1.01 & 44.7 \\
1.34 & 25.6 \\
1.66 & 15.6 \\
1.93 & 7.10 \\
2.28 & 5.24 \\
2.63 & 3.02 \\
3.43 & 0.84 \\
5.30 & 0.117 \\
7.22 & 0.073 \\
10.3 & 0.073 \\
13.5 & 0.022 \\
\hline
\end{tabular}

The partition coefficient of RuD was also determined by a method similar to the second one for RuT. A solution of nitrosylruthenium nitrates in $1 \mathrm{M}$ nitric acid was extracted four times with $30 \%$ tributyl phosphate. Since $q_{\mathrm{T}}$ is high, all RuT is effectively removed. The solution was then extracted once more, and the organic phase, containing essentially pure RuD, was removed and extracted at $20^{\circ}$ with nitric acid of the desired strength. The partition coefficient $q_{\mathrm{D}}$ was obtained from the ratio between the activities in the phases after due correction for the formation of RuT and RuM during the experiment. The results are tabulated in Table 11.

All the data from these experiments have been plotted versus the acidity of the water phase in Fig. 13. The agreement with other investigations is reasonable with respect to $q_{\mathrm{T}}$. The values of $q_{\mathrm{D}}$ are in agreement with measurements using repeated extractions of a water phase (page 1490).

(d) The stability of nitrosylruthenium dinitrate in $30 \%$ tributyl phosphate. A solution of RuD in $30 \%$ tributyl phosphate (saturated with $0.95 \mathrm{M}$ nitric acid) was prepared in the way described in the preceding section. The solu-

Acta Chem. Scand. 13 (1959) No. 8 
Table 11. The acidity dependence of $q_{\mathrm{D}}$.

\begin{tabular}{|c|l|}
\hline Acidity, $\mathrm{M}$ & $q_{\mathrm{D}}$ \\
\hline 0.182 & 0.302 \\
0.396 & 0.341 \\
0.602 & 0.304 \\
0.794 & 0.258 \\
1.42 & 0.141 \\
1.86 & 0.079 \\
2.70 & 0.023 \\
3.50 & 0.013 \\
5.46 & 0 \\
7.48 & 0 \\
\hline
\end{tabular}

tion was kept at $20^{\circ}$. Samples were taken for extraction with $0.95 \mathrm{M}$ nitric acid, and the ratio between the activity of the organic phase and that of the water phase was determined. This ratio is shown in Fig. 14 as a function of the time between the preparation of the solution and the extraction.

If it is assumed that the solution contains only RuT and RuD, their concentrations can be calculated from the activity ratios. From the time-dependence of the concentrations, the rate constant $k_{\mathrm{TD}, o}=0.0067 \mathrm{~min}^{-1}$ is obtained. This agrees well with the value $0.0059 \mathrm{~min}^{-1}$ determined earlier.

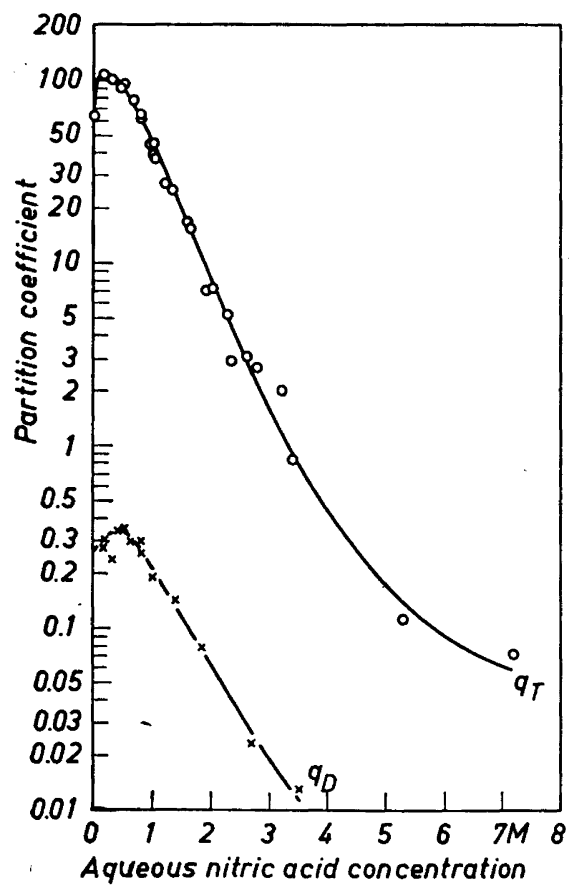

Fig. 13. The acidity dependence of the partition coefficients tor extractions with $30 \%$ tributyl phosphate at $20^{\circ}$. Circles: $q_{\mathrm{T}}$; Crosses: $q_{\mathrm{D}}$.

Acta Chem. Scand. 13 (1959) No. 8 
Fig. 14. The ratio between the activity of the organic phase and that of the water phase versus time for extractions of a solution of originally pure RuD in $30 \%$ tributyl phosphate with $0.95 \mathrm{M}$ nitric acid.

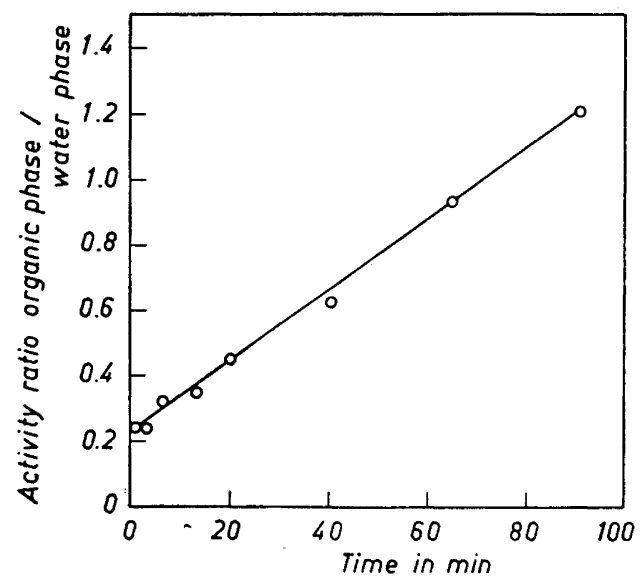

(e) Upper limits for $q_{\mathrm{M}}$ and $q_{\mathrm{N}}$. A large number of experiments concerning the partition coefficients $q_{\mathrm{M}}$ and $q_{\mathrm{N}}$ have been performed. The experiments were carried out at $20^{\circ}$ with the system $30 \%$ tributyl phosphate $-0.95 \mathrm{M}$ nitric acid. Upper limits of the partition coefficients are immediately obtained from repeated extractions of water phases. For large values of the extraction number $n$, the ratio between the activity of the organic phase and that of the water phase varies from 0.03 for solutions containing much RuM and little $\mathrm{RuN}$ to less than 0.005 for solutions containing mainly RuN. Thus

$$
q_{\mathrm{M}}<0.03 \text { and } q_{\mathrm{N}}<0.005
$$

Fig. 15. The ratio between the activity of the organic phase and that of the water phase at the 25th extraction of a water phase with $30 \%$ tributyl phosphate versus $c_{\mathbf{M}} /\left(c_{\mathbf{M}}+c_{\mathbf{N}}\right)$. Temperature: $20^{\circ}$.

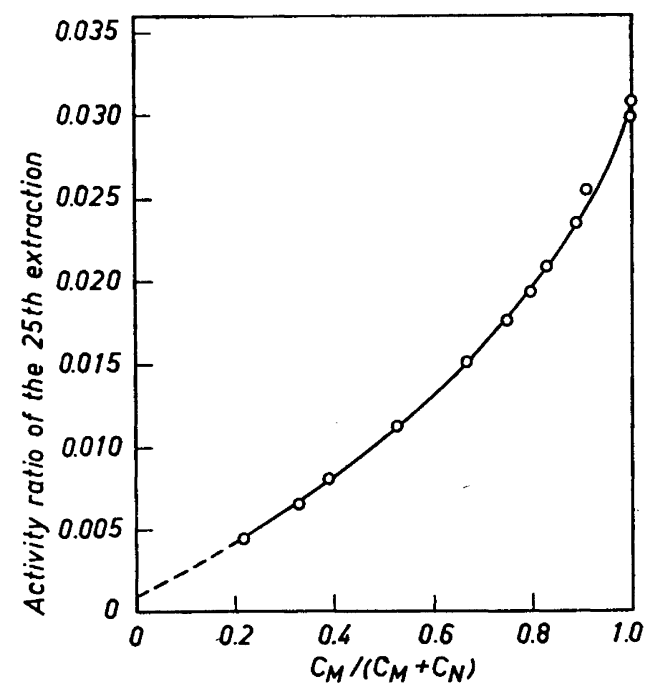

Acta Chem. Scand. 13 (1959) No. 8 
The activity ratio for $n$ equal to 25 has been plotted versus the ratio $c_{M} /\left(c_{\mathbf{M}}+c_{N}\right)$ in Fig. 15. By extrapolation the upper limit 0.001 is obtained for $q_{\mathrm{N}}$.

A better estimate of the upper limit of $q_{\mathrm{M}}$ can be made. A solution of nitrosylruthenium nitrates in $0.95 \mathrm{M}$ nitric acid was extracted four times with $30 \%$ tributyl phosphate. The fourth organic phase was extracted with $0.95 \mathrm{M}$ nitric acid at $20^{\circ}$, and the ratio between the activities of the phases was measured. Four determinations gave the value $0.260 \pm 0.006$ as an average. This corresponds to a $q_{\mathrm{D}}$-value of 0.245 , in excellent agreement with earlier results. In another series of experiments carried out at the same conditions, a water phase was extracted 25 times with $30 \%$ tributyl phosphate, and the 25th organic phase was extracted with $0.95 \mathrm{M}$ nitric acid. The activity ratio $0.237 \pm 0.013$ was obtained as an average of seven determinations. This is close to the $q_{\mathrm{D}}$-value at the given conditions, and the conclusion can be drawn that almost all extracted ruthenium is in the form of RuD. The observed difference between 0.260 and 0.237 corresponds to a $q_{\mathrm{M}}$-value of 0.003 . It should be safe to estimate the upper limit of $q_{\mathrm{M}}$ to 0.01 .

Since both $q_{\mathrm{M}}$ and $q_{\mathrm{N}}$ are small, their neglection in this work is justified.

\section{DISCUSSION}

The method of repeated extractions has proved to be very useful for the study of the nitrato complexes of nitrosylruthenium. Owing to the possibility of taking the interchange between the complexes during the experiment into account, reliable determinations of concentrations and partition coefficients can be made.

The values determined for rate constants, equilibrium concentrations, and partition coefficients make possible predictions of the behaviour of the nitrosylruthenium nitrates at different conditions with respect to the tributyl phosphate concentration, the nitric acid concentration, the temperature, and the time schedule followed during the experiment. Such predictions are of value in connection with those separation procedures for plutonium and uranium which are based on extractions with tributyl phosphate.

It must be pointed out that the present work has not been concerned with any confirmation of the formulas of the nitrosylruthenium complexes. The trinitrate has been identified merely by its partition coefficient and by comparison with other experiments ${ }^{6,8}$. The identities of the other complexes found have been inferred from their relationships (for instance: a solution of RuD in tributyl phosphate is converted into RuT; a solution of RuM in dilute nitric acid is converted into $\mathrm{RuD}$ and not directly into RuT). Furthermore, RuT is probably the most nitrate-rich complex since it dominates at high nitric acid concentrations. Thus, if the identification of RuT as the trinitrate is correct, the identification of the other complexes as the dinitrate, the mononitrate and a nitrate-free complex seems plausible.

The technique of repeated extractions should be useful also for other investigations where a complex mixture of extractable compounds is to be analysed. 
Acknowledgements. The author wishes to express his gratitude to Professor The Svedberg for his interest in this work. ments.

Thanks are due to Mrs. Carina Kjellson for her valuable help in carrying out the experi-

The investigation has been financially supported by AB Atomenergi, which is gratefully acknowledged.

\section{REFERENCES}

1. Katcoff, S. Nucleonics 16 No. 4 (1958) 78.

2. Bruce, F. R. Intern. Conf. Peaceful Uses of Atomic Energy Paper 719 (1955).

3. Fletcher, J. M. and Martin, F. S. Ibid. Paper 437 (1955).

4. Fletcher, J. M., Jenkins, I. L., Lever, F. M., Martin, F. S., Powell, A. R. and Todd, R. J. Inorg. \& Nuclear Chem. 1 (1955) 378.

5. Jenkins, I. L. and Wain, A. G. Ibid. 3 (1956) 28.

6. Brown, P. G. M., Fletcher, J. M. and Wain, A. G. UKAEA Report AERE C/R 2260 (1957).

7. Brown, P. G. M., Fletcher, J. M., Hardy, C. J., Kennedy, J., Scargill, D., Wain, A. G. and Woodhead, J. L. Second United Nations Intern. Conf. Peaceful Uses of Atomic Energy Paper 31 (1958).

8. Zvyagintsev, O. E., Nikolsky, V. D., Starostin, S. M., Kurbanov, A. and Schmidt, V. S. Ibid. Paper 2143 (1958).

9. Fletcher, J. M. J. Inorg. \& Nuclear Chem. 8 (1958) 277.

10. Ayres, G. H. and Young, F. Anal. Chem. 22 (1950) 1281.

11. Allen, R. J. and DeSesa, M. A. Nucleonics. 15 No. 10 (1957) 88.

Received May 12, 1959. 